\title{
INTERAÇÃO SILÍCIO E INSETOS-PRAGA: DEFESA MECÂNICA OU QUÍMICA?
}

\author{
Joelma Melissa Malherbe Camargo ${ }^{1}$, Jair Campos Moraes $^{2}$, Keti Maria Rocha Zanol ${ }^{3}$, Dalva \\ Santana Luiz de Queiroz ${ }^{4}$ \\ ${ }^{1,3}$ Departamento de Zoologia, Curso de Pós-Graduação em Entomologia - Universidade Federal do Paraná/UFPR, Caixa Postal \\ 19020 - Curitiba, PR. melissajoelma@yahoo.com.br \\ ${ }^{2}$ Engenheiro Agronômico, Doutor em Fitotecnia - Departamento de Entomologia/DEN - Universidade Federal de Lavras/UFLA \\ - Cx. P. 3037 - 37200-000 - Lavras, MG \\ ${ }^{4}$ Pesquisador Embrapa Florestas - Estrada da Ribeira, Km 111, 83411-000 - Colombo, PR
}

\section{RESUMO}

As plantas em geral, podem ser suscetíveis às agressões causadas por agentes bióticos e abióticos. Entretanto podem reagir a essas agressões por meio de mecanismos de defesa mecânica e química. A barreira ou defesa mecânica proporcionada pelo silício nas células está ligada à modificação da anatomia da planta, como o aumento da espessura das células, presença de tricomas que atuam na defesa contra o ataque de insetos. O inseto pode apresentar modificações ou alterações em seu aparelho bucal devido à presença de compostos secundários presentes na planta hospedeira, que impedem ou dificultam a alimentação do mesmo. A barreira ou defesa química ocorre quando há síntese de compostos fenólicos ou fitoalexinas que ocasionam aumento da concentração das proteínas ligadas diretamente à defesa da planta contra o ataque de insetos. Tais compostos quando presentes no hospedeiro atuam de forma que o inseto tende a não se alimentar de determinadas plantas, pois o alimento torna-se impalatável, ou seja, não ocorre dificuldade na alimentação, mas não-preferência a tais plantas. Mesmo com a ocorrência natural da resistência a determinados fatores, tais plantas podem apresentar estes mecanismos de defesa de maneira inativa ou latente, e somente ativá-los após a utilização de agentes indutores, como é o caso do silício. Esse micronutriente quando utilizado e incorporado à adubação de plantas age de forma a induzir a resistência de plantas a insetos-praga. O propósito deste trabalho foi realizar um levantamento atualizado sobre a utilização e o emprego do silício no controle de insetospraga em diferentes culturas, dando enfoque e elucidando o tipo de defesa empregado pelas plantas em relação ao ataque de insetos sugadores e mastigadores.

Palavras-chave: Herbivoria, resistência, defesa induzida

\begin{abstract}
Plants in general can be susceptible to the aggressions caused by biotic and abiotics factors. However, they are able to react against these aggressions by the use of the defense mechanisms such as mechanical and chemical barriers. The mechanical barrier provided by the silicon in the cells is related to the modification of plant anatomy, such as the increase of the thickening of the cell and the presence of trichomes acting as an agent against the attack of insects. The insects may present modifications or alterations in their mouth parts due to the presence of secondary compounds in the host plant, which makes feeding difficult. The chemical or defense barrier occurs when there is synthesis of phenolic compounds or phytoalexins that causes the increase of
\end{abstract}


the protein concentration that act directly in the plant defense against insect attack. When these compounds are present in the host, they act in a way that the insect does not feed on some plants because the food becomes unpalatable; in other words, the insect has no difficulty to eating but changes its preference to other kinds of plants. Even with the natural presence of the resistance of determined factors, such plants can present these defense mechanisms in an inactive or latent way, and activate them just after the use of inductive agents, as occur with the silicon. When the micronutrients are used and incorporated into plant fertilization, they act inducing the plant resistance against pests of insects. The purpose of this work was to make an updated data collection about the use of the silicon in the pest insect control in different cultures, focusing on and clarifying the type of defense used by plants in relation to sucking and chewing insects.

Key words: Herbivory, resistance, induced defense

\section{INTRODUÇÃO}

A condição nutricional da planta é um dos fatores que pode afetar a capacidade de suporte da planta em relação a populações de insetos (Raven et al., 1996). De modo geral, plantas que sofrem estresse hídrico ou nutricional constituem melhor fonte de alimento do que plantas não-estressadas, provavelmente por possuírem menor concentração de compostos de defesa (White, 1969).

Rhoades (1979) complementou a hipótese de que as plantas estressadas sintetizam poucas defesas e que este fato, associado à questão nutricional, torna a planta um hospedeiro atrativo a insetos herbívoros.

Pequenas diferenças nutricionais são capazes de causar grandes mudanças no equilíbrio dos níveis populacionais de insetos, ponto este considerado de suma importância na busca para a resistência da planta ao ataque de pragas (Emden, 1978). Variedades de espécies de plantas hospedeiras, sob diferentes condições de adubação, podem causar efeitos adversos sobre a taxa de reprodução, crescimento e longevidade de insetos que delas se alimentam (Evans, 1937).

Qualquer tipo de adubação que favoreça as condições fisiológicas da planta poderá conferir-lhe resistência, tendo em vista que ao fornecer-lhe os diversos nutrientes que lhe são necessários e nas proporções relativas às suas necessidades efetivas, mantêm-na em equilíbrio nutricional, possibilitando resistir mais ao ataque de agentes externos, como os insetos. Conseqüientemente, trata-se de fornecer à planta os diversos elementos que ela exige, na proporção relativa à sua necessidade efetiva. Por outro lado, tanto o excesso como a carência de um ou de diversos elementos que rompem o equilíbrio fisiológico normal da planta são capazes de diminuir sua resistência natural (Labrousse, 1932).

Boiça Júnior \& Alonso (2000) ressaltam que a manifestação da resistência pode ser afetada por vários fatores ambientais, incluindo algumas práticas culturais, como adubação, e poderia ser mais bem explorada no manejo de pragas (Emden, 1966; Gallo et al., 2002; Lara, 1991).

As deficiências e desequilíbrios nutricionais provocam mudanças morfológicas e bioquímicas na planta, podendo tornar certos materiais genéticos mais suscetíveis ao ataque de insetos. $\mathrm{O}$ uso eficiente das adubações aliadas à resistência dos materiais genéticos pode reduzir o nível de severidade e de incidência de insetospragas (Silveira \& Higashi, 2003).

A adubação de plantas apresenta efeitos positivos e negativos na incidência de pragas e doenças (Maxwell, 1972, citado por 
Bortoli \& Maia, 1994; Rodrigues, 1972, citado por Bortoli \& Maia 1994; Primavesi, 1988; Patriquin et al., 1993, Bortoli \& Maia 1994).

Enquanto Chaboussou (1987) e Primavesi (1988) ressaltam a importância do equilíbrio nutricional para se evitarem doenças e pragas, Maxwell (1972), citado por Bortoli \& Maia (1994), considerou que os insetos ficam com menos vigor devido à nutrição inadequada das plantas e, conseqüentemente, mais vulneráveis à ação dos produtos químicos e biológicos usados no seu controle.

Entre as diversas técnicas utilizadas para manter as populações de insetos considerados pragas, abaixo do nível de dano econômico, a nutrição de plantas com elementos promotores ou indutores de resistência a moléstias associados com técnicas de controle químico ou biológico, despontam como promissoras.

De acordo com Marschner (1995) o emprego da nutrição mineral aumenta a resistência de plantas a insetos praga. Dessa forma vários estudos estão sendo realizados no Brasil no sentido de associar o ataque de insetos a plantas a partir da adubação ou acumulação de silício nas plantas.

A indução de resistência em plantas apresenta-se como uma das alternativas mais viáveis, juntamente com o controle biológico e o plantio de materiais com fontes de resistência genética, para reduzir os danos de insetos a culturas em geral. Essa resistência induzida em plantas pode ser obtida pela aplicação de produtos químicos.

Desse modo, a utilização do silício em diversas culturas, tem desempenhado um papel importante na proteção de algumas espécies vegetais contra o ataque de insetos.

O silício, embora não faça parte da lista dos elementos essenciais é considerado elemento útil para o crescimento e produção de muitas culturas (Barbosa Filho et al., 2000), e sua absorção traz inúmeros benefícios especialmente quando estas estão submetidas a estresse biótico ou abiótico. Além disso, a presença desse elemento nos tecidos vegetais tem sido citada por diversos autores como uma importante ferramenta na redução da intensidade de doenças em várias culturas (Santos et al., 2007).

Desse modo, o micronutriente vem demonstrando importante papel na nutrição e proteção de algumas espécies vegetais ao ataque de insetos. A adubação das culturas com produtos ricos em silício resultam em aumentos significativos no crescimento e na produtividade de muitas gramíneas e em algumas espécies não gramíneas têm sido observados aumentos de produtividade com o aumento de disponibilidade de silício no solo (Camargo et al., 2008)

A ausência do silício pode ocasionar uma diminuição da capacidade biológica da planta em resistir às condições adversas do meio ambiente onde vive (Rafi et al., 1997). Pelo fato de estar amplamente distribuído na natureza torna-se difícil comprovar, cientificamente, a sua essencialidade às plantas. $\mathrm{O}$ fato mais importante atualmente é que a Legislação Brasileira de Fertilizantes passou a considerar o silício como um micronutriente benéfico às diversas culturas e sua incorporação aos fertilizantes NPK tornou-se obrigatória de acordo com o Decreto Lei 4.954 de 14 de janeiro de 2004 (Rodrigues et al., 2001).

Por ser encontrado na natureza o silício não apresenta os mesmos problemas causados por inseticidas. Normalmente o silício utilizado no controle de insetos considerados pragas de diversas culturas é obtido de atividades siderúrgicas passando por diversos processos para retirada da toxidez causada pela presença de metais pesados.

Acredita-se que esse micronutriente possa diminuir a incidência do ataque de insetos, conferindo maior proteção à planta. Isso ocorre devido à acumulação de silício abaixo da cutícula das folhas, que oferece resistência contra esses organismos. 
Absorvido pelas raízes junto com a água, o silício tende a acumular-se nas folhas formando uma barreira protetora contra $o$ ataque dos insetos .

As interações entre as plantas e seus predadores têm profundas implicações, tanto para a ecologia quanto para os processos evolutivos dos mesmos (Basset, 1994). O autor considera a importância das interações, particularmente nos trópicos, onde uma forte seleção, em plantas e herbívoros, tem promovido maiores níveis de herbivoria e de investimento para a defesa, comparando com espécies de ambientes temperados.

Pais (2003) afirma que essas
interações influenciam, de modo significativo, a sucessão ecológica, uma vez que espécies muito atacadas podem ter suas populações diminuídas, em detrimento de outras não tão atrativas para os herbívoros. Segundo Coley \& Barone (1996) e Medeiros \& Morretes (1995), herbívoros provocam numerosos efeitos negativos na capacidade reprodutiva e crescimento das plantas, reduzindo sua habilidade competitiva. Dessa forma, as plantas desenvolvem características morfológicas e químicas capazes de inibir o ataque dos insetos herbívoros ou, até mesmo selecionando herbívoros favoráveis, como aqueles que vão atuar na defesa da planta.

As plantas exibem uma variedade de mecanismos defensivos e modificações impressionantes a fim de reduzir a perda de tecido fotossintético pelos herbívoros (Cates, 1975). Harborne (1988) dividiu as defesas em mecânica e química. Entre os mecanismos de defesa mecânica estão os depósitos cuticulares, uma maior espessura da epiderme, a abundância de cristais, tricomas, fibras e a dimensão e disposição dessas estruturas e tecidos na folha. As defesas químicas, também importantes, são representadas pela presença de compostos secundários com propriedades tóxicas ou repelentes. Tais mecanismos reduzem a probabilidade de dano aos tecidos da planta, por alterar a palatabilidade para os insetos.

Diante de tais fatos, este trabalho tem como objetivo revisar trabalhos realizados com o intuito de verificar o efeito da aplicação de silício em plantas e a indução de resistência a insetos-praga visando elucidar a causa da resistência, ou seja, quais são os mecanismos de defesa da planta atuantes e envolvidos no contexto silício $\mathrm{x}$ inseto.

\section{INTERAÇÃO INSETO-PLANTA}

Os insetos são os principais consumidores da produção primária terrestre, constituindo cerca de $80 \%$ da vida animal e, aproximadamente, um terço de todas as espécies conhecidas (Thomanzini \& Thomanzini, 2000). Apresentam hábito herbívoro, ao menos em uma fase do seu ciclo de vida, desempenhando um importante papel ecológico, atuando como predadores, parasitas, polinizadores, entre outros (Edwards \& Wratten, 1981).

As interações entre as plantas e seus predadores têm profundas implicações, tanto para a ecologia quanto para os processos evolutivos dos mesmos, pois influenciam significativamente a sucessão ecológica, provocando efeitos negativos no crescimento e na capacidade reprodutiva das plantas (Edwards et al., 1981; Basset, 1994; Lowman, 1995; Sargersm, 1995; Coley \& Barone, 1996; Melo \& Silva-Filho, 2002; Pais, 2003).

As plantas não são passivas às injúrias causadas por agentes bióticos e nãobióticos e dessa forma, desenvolveram mecanismos de respostas ou de defesas contra o ataque de insetos (Lara, 1991, Pinheiro et al., 1999).

Após a seleção ocorre o processo de aceitação e posteriormente ocorre o ataque por parte dos insetos a determinadas plantas, que normalmente são capazes de reagir a agressões causadas tanto por agentes 
bióticos e abióticos por meio de respostas de defesas como as barreiras mecânicas e químicas. A resposta a essas agressões é acionada mediante a interação entre a molécula elicitora e proteínas da membrana das células vegetais (Dias \& Rangel, 2007)

Características estruturais foliares e substâncias químicas produzidas pelas plantas com a finalidade de defesa podem influenciar a distribuição e a intensidade do ataque de insetos. O conhecimento dessas características estruturais favorece a compreensão das relações interespecíficas, da preferência de insetos fitófagos e mastigadores por determinadas espécies e da definição de possíveis padrões anatômicos determinantes dos níveis de herbivoria na planta (Coley \& Barone, 1996).

Segundo Melo e Silva-Filho (2002), as plantas produzem dois tipos de substâncias de defesa: constitutivas que são substâncias que repelem os herbívoros provocando toxicidade direta ou reduzindo a digestibilidade do tecido vegetal, e substâncias induzidas que são aquelas sintetizadas em resposta ao dano causado ao tecido pelos herbívoros.

A utilização de estratégias de defesa como essas, permitem a prevenção no aumento do número de herbívoros, embora exista um número reduzido de insetos que se adaptam a uma determinada espécie vegetal. Tais substâncias conferem à planta uma melhor capacidade reprodutiva, uma vez que os tecidos responsáveis pela fotossíntese são conservados (Melo \& Silva-Filho, 2002).

Harborne (1988) dividiu as defesas em químicas e físicas, mas atualmente autores como Moraes et al. (2005). Gomes et al. (2005) e Goussain et al.(2002) dividem tais defesas em mecânicas e químicas.

As defesas mecânicas são aquelas que atuam negativamente sobre o inseto seja pela formação de depósitos cuticulares, epiderme espessada, abundância de cristais, tricomas ou fibras nas folhas. As defesas químicas que se caracterizam por serem metabólitos tóxicos ou repelentes, atuam minimizando o dano e reduzindo a preferência do inseto a tais plantas hospedeiras (Fernandes, 1994).

A epiderme foliar é coberta por cutícula lipídica, a qual forma uma barreira mecânica contra a penetração de fungos e a ação de insetos herbívoros. A cutícula mais espessa e a dureza foliar pode dificultar a alimentação dos insetos, pois apresentam paredes mais espessadas ou feixes de fibras, lignificadas ou não (Edwards \& Wratten, 1981).

Uma epiderme com textura rígida, por deposição de sílica ou lignina, é uma barreira mecânica que reduz a oviposição de alguns insetos (Lara, 1991) e assim a performance de um determinado inseto pode ser limitada ou influenciada por tais atributos da planta hospedeira. Entre os fatores que influenciam essa interação, destacam-se as barreiras ou defesas mecânicas e químicas.

O silício pode promover menor incidência no ataque de insetos a plantas por meio de formação de barreiras mecânicas pela alteração das respostas bioquímicas da planta ao ataque dos mesmos, ou químicas aumentando a síntese de toxinas que podem agir como substâncias inibidoras ou repelentes (Marschner, 1995).

As barreiras mecânicas incluem mudanças na anatomia das plantas, como células epidérmicas mais grossas e maior grau de lignificação ou silicificação (acúmulo de silício). As barreiras mecânicas podem incluir mudanças na anatomia das plantas, como células epidérmicas mais grossas e um grau maior de lignificação e/ou silicificação (acúmulo de silício) (Blum, 1968; Marschner, 1988; Epstein, 1994; Dannon \& Wydra, 2004).

Quando ocorre a silicificação (deposição de silício) das células epidérmicas, há maior dificuldade da penetração do estilete de insetos sugadores 
formando assim uma barreira mecânica. O acúmulo e a polimerização de silício na célula epidérmica, logo abaixo da cutícula, formam uma barreira mecânica denominada "dupla camada silício-cutícula", ajudando a manter as folhas mais eretas, diminuindo a transpiração e protegendo as plantas contra o ataque de insetos-praga (Yoshida et al., 1962, citados por Savant et al., 1997).

A barreira mecânica proporcionada pelo silício nas células não é o único mecanismo de resistência ao ataque de insetos. Resultados recentes sugerem que o elemento age no tecido do hospedeiro afetando os sinais entre o hospedeiro e o inseto, resultando em ativação mais rápida e extensa dos mecanismos de defesa da planta (Goussain, 2006).

O mecanismo pelo qual o silício exerce seu efeito protetor ao ataque de insetos é ainda controverso. A função do silício como reforço da resistência mecânica é questionado por diversos autores, mas Chérif (1982) relaciona o seu uso com reações específicas de defesa das plantas. Gomes et al. (2005) corroboram tal afirmação e sugerem que o silício atua também como elicitor do mecanismo de resistência induzida, ou seja, as plantas apresentam mudanças fisiológicas e morfológicas em resposta à herbivoria ou outro tipo de estresse.

Plantas ricas em metabólitos secundários garantem vantagens para a sobrevivência. Os metabólitos são classificados quanto à estrutura química: nitrogenados, terpenóides e fenólicos. Normalmente tais compostos podem não ser caracterizados como essenciais para 0 organismo e além de garantir a sobrevivência são relacionados diretamente com a perpetuação das espécies no planeta. Apesar dos metabólitos secundários serem considerados produtos de excreção do vegetal, sem função definida alguns auxiliam no ajuste das plantas ao meio (Santos, 2004).
Os compostos vegetais secundários dividem-se em três grandes classes. Estimase que o número desses compostos ultrapasse 400 mil, estes são: nitrogenados, terpenóides e fenólicos os quais podem ser encontrados em várias partes da planta e as concentrações variam com a idade (Harbone, 1988; Lara, 1991; Rhodes, 1994).

Em muitas plantas, onde ocorre a atuação de barreiras ou defesas químicas a partir da liberação de compostos há também a redução da disponibilidade de proteínas para herbívoros. Estes compostos se ligam às proteínas inibindo a digestão, retardando o crescimento de herbívoros, podendo interferir em vias metabólicas específicas ou em processos fisiológicos dos mesmos (Harbone, 1988; Rhodes, 1994).

De acordo com diversos autores, quando ocorre aplicação de silício há o aumento do grau de resistência das plantas diminuindo a preferência de insetos-praga por determinadas plantas.

Goussain et al. (2005) verificaram que alterações químicas e a indução de resistência estão provavelmente envolvidas na redução da performance do pulgão-verde Schizaphis graminum, sem, entretanto, alterar seu período de alimentação. Nesse caso, é possível verificar a atuação das defesas químicas, pois a penetração de estiletes não foi afetada pelos tratamentos com silício que resultaria como barreira mecânica.

O xilema e o floema foram igualmente alcançados em todos os tratamentos e os pulgões continuaram se alimentando no floema por períodos similares. Entretanto, a excreção de honeydew foi reduzida no tratamento com silício, indicando menor taxa de ingestão ou maior retenção de seiva no corpo do pulgão (Goussain et al., 2005). A menor taxa de ingestão pode ser caracterizada pela impalatabilidade dessas plantas submetidas à aplicação de silício. 


\section{O SILÍ́CIO NO SOLO E NAS PLANTAS}

A palavra silício provém do latim silex, rocha constituída de sílica (dióxido de silício) amorfa hidratada e sílica microcristalina, a qual era utilizada, pela sua dureza, na confecção de utensílios e armas na Era Pré-Metálica (Paleolítica). O silício é o segundo elemento mais abundante da crosta terrestre, sendo superado apenas pelo oxigênio (Elawad \& Green Júnior, 1979). É encontrado somente em formas combinadas como a sílica $(\mathrm{SiO} 2)$ e minerais silicatados (Lima Filho et al., 1999).

Mesmo não sendo considerado essencial do ponto de vista fisiológico e metabólico para o crescimento e desenvolvimento de plantas, a absorção do silício traz inúmeros benefícios (Epstein, 1994). O autor ressalta que plantas crescendo em ambiente rico em silício devem diferir daquelas presentes em ambientes deficientes nesse elemento, principalmente quanto à resistência mecânica das células, características de superfície foliar, tolerância ao estresse abiótico, e ao ataque de fungos e pragas.

$\mathrm{O}$ silício ao ser absorvido pelas plantas é facilmente translocado no xilema, e tem a tendência natural de se polimerizar (Barber \& Shone,1966; Datnoff et al., 2001).

De acordo com Yoshida (1975), a única forma absorvida pelas plantas ocorre na forma de monômeros de ácido silícico $\left(\mathrm{H}_{4} \mathrm{SiO}_{4}\right)$. No interior da planta, $99 \%$ do total acumulado encontram-se na forma de ácido silícico polimerizado, o qual é de difícil solubilização. o restante, menos de $1 \%$, encontra-se na forma coloidal ou iônica.

A maior parte de silício é depositado nas folhas ( $71 \%$ do total), seguido pela casca (13\%), raízes (10\%) e colmo (6\%) (Yoshida, 1975).

O silício está presente na solução do solo como ácido monossilícico, a maior parte na forma não dissociada (pK1 = 9,6), o qual é prontamente absorvido pelas plantas
(Raven, 1983; Werner \& Roth, 1983; Wild, 1988). As principais fontes de ácido silícico na solução do solo são provenientes da decomposição de resíduos vegetais, dissociação do ácido silícico polimérico, liberação de silício dos óxidos e hidróxidos de $\mathrm{Fe} \mathrm{e} \mathrm{Al}$, dissolução de minerais cristalinos e não cristalinos, adição de fertilizantes silicatados, e a água de irrigação.

O silício pode ser encontrado no solo como sílicas cristalinas e amorfas, como silicatos de $\left(\mathrm{H}_{4} \mathrm{SiO} 4\right)$ e $\mathrm{Mn}$, e como sílica dissolvida na solução do solo (Lima Filho et al., 1999).

A concentração e a disponibilidade de silício na solução do solo são dependentes da rocha de origem, do grau de intemperismo, do $\mathrm{pH}$ do solo e do teor de sesquióxidos e de outras partículas adsorventes (Takahashi, 1995).

As principais formas de silício no solo, passíveis de serem absorvidas pelas plantas, são o ácido monosilícico (H4SiO4) e o ácido polisilícico, incluindo silício adsorvido, quer seja solúvel ou precipitado junto com óxidos cristalinos de Al, Fe e Mn (Takahashi, 1995). As plantas podem ser classificadas em relação ao acúmulo de $\mathrm{Si}$, como acumuladoras, intermediárias e nãoacumuladoras, incluindo assim a maioria das dicotiledôneas, como leguminosas e várias espécies arbóreas (Miyake \& Takahashi, 1983).

As fontes tradicionalmente utilizadas são os silicatos de cálcio, potássio, magnésio ou escórias de siderurgia que apresentam baixíssimos teores de silício solúvel.

Em algumas pesquisas são utilizados metassilicatos de sódio e potássio, além do ácido silícico, com efeito semelhante. O metassilicato de potássio é utilizado na Europa, principalmente por produtores de pepino e roseiras, para o controle de míldio por meio de pulverização foliar (Bélanger $e t$ al., 1995). 
Comercialmente, as escórias básicas de siderurgia, que são silicatos de cálcio e magnésio, além de poderem ser utilizadas como corretivos do solo devido à sua basicidade, são fontes de silício. Os termofosfatos magnesianos (silicofosfatos de magnésio) também se caracterizam como fontes.

Com a aprovação da comercialização do silicato de potássio como fonte de silício pela legislação brasileira, vem viabilizandose o uso dessa fonte na aplicação de silício via foliar (Rodrigues et al., 2004)

A comprovação da essencialidade do silício é muito difícil de ser obtida, devido à sua abundância na biosfera. O mesmo está presente em quantidades significativas mesmo em sais nutrientes, água e ar altamente purificados (Werner \& Roth, 1983). Apesar disso, o fornecimento de silício é benéfico para muitas espécies vegetais e, em determinadas circunstâncias, para a maioria das plantas superiores (Marschner, 1995).

Entretanto, o Decreto $\mathrm{n}^{\mathrm{o}} 4.954$, de 14/01/2004, que regulamenta a Lei 6.894, alterada pela Lei 6.934 constata a importância da adubação com silício e o elemento foi incluído formalmente na relação de nutriente essencial ou benéfico para o crescimento e produção dos vegetais, tendo sido classificado, mais precisamente como micronutriente (Brasil, 2007).

O silício após ser absorvido é depositado principalmente, na parede celular, causando assim um aumento na rigidez das células (Adathia \& Besford, 1986). Tais células ficam mais grossas e com maior grau de silificação formando uma barreira que apresenta as funções de limitar a perda de água e de dificultar o ataque dos insetos (Yoshida, 1965).

O silício pode estimular o crescimento e a produção vegetal através de várias ações indiretas, como a diminuição do auto-sombreamento, deixando as folhas mais eretas, decréscimo na suscetibilidade ao acamamento, maior rigidez estrutural dos tecidos, proteção contra estresses abióticos, como a redução da toxidez de $\mathrm{Al}, \mathrm{Mn}, \mathrm{Fe}$ e $\mathrm{Na}$, diminuição na incidência de patógenos e aumento na proteção contra herbívoros, incluindo os insetos fitófagos (Epstein, 1994; Marschner 1995).

A produtividade de muitas gramíneas, como arroz, cana-de-açúcar, sorgo, milheto, trigo, milho e algumas espécies nãogramíneas, apresentam aumentos de produtividade com o aumento da disponibilidade de silício no solo (Elawad \& Green Júnior, 1979; Korndörfer \& Lepsch, 1999).

$\mathrm{Na}$ planta, o elemento concentra-se nos tecidos de suporte do caule e das folhas, oferecendo estrutura e resistência ao acamamento, mas também pode ser encontrado em pequenas quantidades nos grãos e frutos. Segundo Epstein (1999), o teor de silício nas plantas pode variar de 0,1 a $10 \%$. Este ao ser absorvido é capaz de formar uma barreira mecânica à invasão de fungos para o interior das plantas, dificultando também o ataque de insetos sugadores e herbívoros (Mc Naughton \& Tarrants, 1983; Epstein, 1999). O efeito da proteção mecânica é atribuído, principalmente, ao depósito de silício na forma de sílica amorfa $\left(\mathrm{SiO}_{2} \cdot \mathrm{nH}_{2} \mathrm{O}\right)$.

O silício pode proporcionar aumento do grau de resistência das plantas ao ataque de insetos e doenças. Diversos estudos demonstram que o silício se deposita nas células epidérmicas das folhas e tricomas aumentando o espessamento e a rigidez e também atua como um elicitor no sistema de defesa da planta ao ataque de pragas pela produção de compostos fenólicos de defesa (Gomes et al., 2008).

Pesquisas mais recentes demonstraram que o silício quando colocado à disposição das plantas pode aumentar o aproveitamento de nutrientes pelas mesmas, contribuindo para o seu crescimento, além de induzir resistência às doenças fúngicas e 
aos insetos-praga (Lanning \& Linko, 1961; Comhaire, 1965; Chérif et al., 1992).

\section{O SILÍCIO COMO INDUTOR DE RESISTÊNCIA A INSETOS-PRAGA}

A maior resistência ao ataque de insetos por plantas com nível ótimo de silício nos tecidos está sendo alvo de estudo por um número cada vez maior de pesquisadores no Brasil. Alguns resultados de pesquisa incluem o pulgão-verde em trigo e sorgo, lagarta-do-cartucho em milho, broca-do-colmo em cevada, broca-da-canade-açúcar, lagarta-do-colmo em arroz, entre outros insetos-praga de culturas.

A planta pode responder ao estímulo invasor da praga aumentando a absorção de silício, como foi constatado em citros e pastinaca (Lima Filho, 2005).

$\mathrm{O}$ efeito de diferentes fontes de silício sobre o tripes Stenchaetothrips biformis (Bagnall, 1913) (Thysanoptera: Thripidae), foi investigado por Subramanian \& Gopalaswamy (1988). Esses autores concluíram que, nos tratamentos em que foi adicionado silício, o número de tripes/folha foi significativamente menor em relação ao tratamento sem silício.

Kin \& Heinrichs (1982) estudaram o efeito de quatro doses de silício $(0,50,100$ e 150 ppm de $\mathrm{SiO}_{2}$ ) em solução nutritiva, em plântulas de arroz contra ninfa da cigarrinha Sogatella furcifera (Hórvath, 1899) (Hemiptera: Delphacidae). Os autores observaram que poucas ninfas transformaram-se em adultos nas plantas tratadas com silício e que o número de machos cresceu com o aumento da dose desse mineral.

Verificando a influência do silicato de cálcio e do ativador acibenzolar-S-methyl na indução de resistência em pepino no desenvolvimento de Bemisia tabaci biótipo B (Gennadius, 1889) (Hemiptera: Aleyrodidae), Correa et al. (2005) observaram efeito adverso do silicato de cálcio e do ativador acibenzolar-S-methyl na população da mosca-branca pela redução da oviposição, aumento do ciclo biológico e mortalidade na fase de ninfa. Apresentaramse, assim, como produtos alternativos a serem utilizados no manejo integrado da mosca-branca na cultura do pepino.

Para Nilapavarta lugens (Stal, 1854) e S. furcifera, Stenchaetothrips biformis (Bagnall, 1913) (Thysanoptera: Thripidae), mosca-da-galha Latrophobia brasiliensis (Rubsaamen, 1917) (Diptera: Cecidomyiidae), a aplicação de silício contribuiu para a redução da população desses insetos-praga na cultura do arroz (Subramanian \& Gopalaswamy,1988; Salim \& Saxena, 1992).

A diminuição da população dos afídeos Metopolophium dirhodum (Walker, 1848) (Hemiptera: Aphididae) e Sitobion avenae (Fabricius, 1794) (Hemiptera: Aphididae), sobre folhas de trigo após a aplicação foliar de silício $\left(1 \% \mathrm{Na}_{2} \mathrm{SiO}_{2}\right)$ não foi resultado somente da deposição de silício nas células epidérmicas, mas também devido ao aumento da solubilidade desse elemento dentro da folha (Hanisch, 1980).

Uma tática para o controle do pulgãodo-milho Rhopalosiphum maidis (Fitch, 1856) (Hemiptera: Aphididae) seria a utilização de materiais resistentes, porém, por não se tratar de uma praga-chave da cultura, não há, ainda, disponibilidade de genótipos de milho com essas características (Moraes et al., 2005)

Diante disso, Moraes et al. (2005) testaram o efeito do silício na preferência do pulgão-da-folha em plantas de milho, com aplicação de silício via solo e foliar. Verificou-se, nessa pesquisa, que os tratamentos nos quais o silício foi aplicado via solo mais uma adubação foliar, ou mediante duas aplicações foliares, foram os que apresentaram menor número de pulgões, possivelmente devido ao aumento da 
resistência das folhas o que dificultou a alimentação desses insetos.

Gomes et al. (2005) verificaram que a adubação silicatada e a infestação prévia com pulgões induzem resistência em plantas de trigo a Schizaphis graminum (Rondani, 1852) (Hemiptera: Aphididae), onde a aplicação de silício ativou e aumentou a síntese de compostos de defesa da planta de trigo, como peroxidase e polifenoloxidase, reduzindo a taxa de crescimento e também a preferência desse inseto-praga por plantas tratadas com esse mineral.

Carvalho et al. (1999) avaliaram o efeito do silício como indutor de resistência de plantas de sorgo ao pulgão-verde $S$. graminum e obtiveram como resultados, tanto nos testes de preferência com chance como sem chance de escolha, redução na preferência e na reprodução do pulgãoverde.

Dal Pogetto et al. (2007), em estudo utilizando o Agrosilício ${ }^{\circledR}$, avaliaram o efeito da aplicação do micronutriente em plantas de Eucalyptus camaldulensis (Dehn.) no desenvolvimento biológico de Glycaspis brimblecombei (Moore, 1964) (Hemiptera: Psyllidae). Os autores concluíram que a aplicação do Agrosílicio $^{\circledR}$ em mudas do eucalipto causou maior mortalidade das ninfas de $G$. brimblecombei, reduzindo assim significativamente a sua população.

Basagli et al. (2003) realizaram aplicações seqüenciais de solução de silicato de sódio a $0,4 \%$ de $\mathrm{SiO}_{2}$ e constataram que o silício reduziu a preferência, a longevidade e a produção de ninfas do pulgão-verde $S$. graminum, conferindo, portanto, resistência das plantas de trigo ao inseto-praga.

Camargo et al. (2008) avaliaram a aplicação de silício em plantas de Pinus taeda (L.) concluindo que a quantidade de silício acumulado nas plantas afetou tanto a preferência alimentar como a capacidade reprodutiva de Cinara atlantica (Wilson, 1918) (Hemiptera: Aphididae).
No manejo integrado de pragas (MIP), o uso de táticas que visem diminuir a densidade populacional do inseto-praga e que não afetem a sobrevivência e o desenvolvimento biológico de inimigos naturais é primordial.

Estudo realizado para observar o efeito indireto da aplicação de silício em plantas de trigo no desenvolvimento de dois importantes inimigos naturais do pulgãoverde, o predador Chrysoperla externa (Hagen, 1862) (Neuroptera: Chrysopidae) e o parasitóide Aphidius colemani Viereck (Hymenoptera: Aphidiidae), demonstrou que eles não tiveram a biologia alterada quando se alimentaram de pulgões provenientes de plantas tratadas com silício (Moraes et al., 2004).

Moraes et al. (2004) estudaram a interação tritrófica: trigo, pulgão-verde $S$. graminum e seus inimigos naturais chave e verificaram que a aplicação de silício aumentou o grau de resistência das plantas de trigo, diminuindo a preferência do pulgão-verde em relação à testemunha.

Blum (1968), analisando as características anatômicas de genótipos de sorgo quanto à resistência mecânica das plântulas à penetração de larvas da mosca Atherigona varia soccata (Rondani, 1871) (Diptera: Muscidae), observou que os genótipos resistentes caracterizaram-se por distinta lignificação, pela maior espessura das paredes celulares e pela presença de alta densidade de armações de silício (parecidos com halteres) na epiderme abaxial da base das bainhas das folhas.

Adlaka (1964) observou que a suscetibilidade de várias cultivares de canade-açúcar para a broca-do-colmo Scirpophaga nivella (Fabricius, 1794) (Lepidoptera: Pyralidae) estava associada a fatores como o teor de silício das plantas.

Em cultura de arroz, a resistência das plantas à broca-do-colmo Chilo supressalis (Walker, 1863) (Lepidoptera: Pyralidae) foi 
positivamente correlacionada com o teor de silício, determinado em 20 variedades (Djamin \& Pathak, 1967). Os autores concluíram que, nas variedades com alto teor de silício, um menor número de lagartas foi encontrado, diminuindo assim, a porcentagem de coração-morto nas plantas. Verificaram também a alta correlação linear negativa entre a sobrevivência das lagartas e a porcentagem de silício encontrada nas plantas.

Para a espécie Chilo supremain (Walker) (anteriormente supressalis), que também danifica essa cultura, Tayabi \& Azizi (1984) verificaram que a aplicação de $500 \mathrm{~kg} / \mathrm{ha}$ de silicato de potássio proporcionou o aumento do número de panículas/planta, panículas $/ \mathrm{m}^{2}$ e de grãos $/ \mathrm{m}^{2}$, e a redução de mais da metade do número de lagartas por $\mathrm{m}^{2}$. Respostas semelhantes foram observadas por Sawant et al. (1994) para a lagarta-amarela-do-colmo Scirpophaga incertulas (Walker, 1863) (Lepidoptera: Pyralidae), que apresentou com a adição de $2 \mathrm{~kg}$ de casca de arroz carbonizada (rica em silício) $/ \mathrm{m}^{2}$ de canteiro um aumento significativo do teor de silício em plantas de arroz o que diminuiu a porcentagem de coração-morto causado pela lagarta.

Goussain et al. (2005) estudaram o efeito da aplicação de silício em plantas de milho no desenvolvimento da lagarta-docartucho, Spodoptera frugiperda (Smith, 1797) (Lepidoptera: Noctuidae). Não foi observado efeito do silício na duração da fase larval e pupal, peso de pupa e na mortalidade de pupas. Entretanto, verificaram maior mortalidade e aumento de canibalismo em grupos de lagartas ao final do $2^{\circ}$ ínstar, e maior mortalidade de lagartas individualizadas no $2^{\circ}$ e $6^{\circ}$ ínstares, quando foram alimentadas com folhas de plantas de milho tratadas com silício, em comparação com a testemunha.

A resistência de 19 genótipos de capim ao ataque do gorgulho-das-pastagens,
Listronotus bonariensis (Kuschel, 1955) (Coleoptera: Curculionidae) foi estudada por Barker (1989), sendo verificado que o número de oviposições nas plantas foi correlacionado negativamente com a densidade de depósitos de silício na superfície abaxial das bainhas, o que também dificultou a alimentação das larvas.

\section{SILÍCIO: CAUSAS DA RESISTÊNCIA PARA INSETOS SUGADORES E MASTIGADORES - BARREIRA MECÂNICA OU QUÍMICA?}

Entre os principais autores citados neste trabalho, muitos afirmam que somente um tipo de mecanismo de defesa ocorre em relação à aplicação do silício. Há a deposição do silício e consequentemente a formação de barreira mecânica que atua nos insetos dificultando sua alimentação seja pela formação de espinhos ou tricomas ou até mesmo pelo alimento ser considerado impalatável pelo inseto.

Mas em outras pesquisas foi possível verificar que existem dois modos atuantes de defesas, que agem de forma distinta.

A barreira mecânica que seria uma dessas defesas ou barreiras é formada pela aplicação do silício em plantas e atua em insetos mastigadores. A absorção do silício pelas plantas podem formar os tricomas, espinhos ou outras estruturas que dificultam a alimentação dos insetos. A dureza foliar apresentada pelos hospedeiros está relacionada diretamente com o conteúdo de silício no tecido vegetal, pois ao ser absorvido pela planta se polimeriza e não se redistribui mais (Dias \& Rangel, 2007).

$\mathrm{Na}$ cultura de arroz, por exemplo, a resistência das plantas à broca-do-colmo $C$. supressalis foi positivamente correlacionada com o teor de silício (Djamin \& Pathak, 1967). Os autores concluíram que, nas variedades com alto teor de silício um menor número de lagartas foi encontrado. 
Verificaram também a alta correlação linear negativa entre a sobrevivência das lagartas e a porcentagem de silício encontrada nas plantas. A concentração de silício nas plantas, além de afetar a sobrevivência das lagartas, reduziu a alimentação dos insetos, sendo a mortalidade correlacionada com o excessivo desgaste da região incisora da mandíbula, o que é caracterizada pela dureza foliar presente nas plântulas de arroz.

Para a cultura do milho foi verificado que a aplicação do silício também dificultou a alimentação da lagarta-do-cartucho $S$. frugiperda, causando desgaste acentuado na região incisora das mandíbulas das lagartas quando em contato com folhas com maior teor de silício e aumento da mortalidade e canibalismo (Goussain, 2002).

Estudos anteriores sugerem que a barreira mecânica estaria ligada diretamente ao ataque de insetos sugadores, pois a aplicação de silício poderia estar relacionada com a dificuldade da penetração dos estiletes do inseto-praga no tecido da planta.

Em contraste, Goussain et al. (2005), por meio de estudos de EPG (Electrical Penetration Graph), observaram que o período de alimentação de $S$. graminum, não se alterava e que o mesmo não apresentava dificuldade em se alimentar de plantas com aplicação de silício.

Tal observação comprova que a defesa ou barreira formada neste caso, ou seja, atuante em insetos sugadores seria a defesa ou barreira química, pois não há dificuldadepor parte de insetos sugadores em se alimentar, e sim a redução da preferência por determinadas plantas que com aplicação de silício apresentam compostos que repelem tais insetos.

Os insetos realizam a prova mas acabam optando pela procura de outro hospedeiro que não possua compostos que tornam o alimento impalatável.

A defesa ou barreira química atuante em insetos sugadores a partir da aplicação de silício via foliar ou via solo, pode afetar características como o período reprodutivo, longevidade e fecundidade do inseto. Tal resultado pode estar relacionado a um efeito detrimental direto do produto ou indireto por meio da indução de compostos químicos de defesa da planta pela aplicação de silício. Uma sequência de mudanças bioquímicas tem sido reportada em plantas tratadas com silício, incluindo aumento da produção de quitinase, peroxidase e polifenoloxidase (Chérif et al., 1992; Samuels et al., 1993; Chérif et al.,1994).

Gomes et al. (2005) verificaram que a aplicação de silicato de cálcio em plantas de trigo afetou a taxa de crescimento populacional do pulgão-verde $S$. graminum em relação à testemunha (sem silício). Esse resultado foi relacionado a um aumento na produção de compostos da planta pela ativação de enzimas de defesa como peroxidase, polifenoloxidase e fenilalanina amônia-liase.

O estudo realizado por Goussain et al. (2005) demonstrou que o impedimento na superfície e epiderme para a penetração do estilete não é afetado pela aplicação de silício, mas a aplicação de silício induz os afídeos a retirarem o estilete das plantas. Esses insetos são capazes de ingerir o conteúdo floemático, entretanto há um gasto de tempo maior para atingir o floema em plantas tratadas com silício.

O período de ingestão no floema não é afetado e, pelos resultados é possível sugerir que o silício induz algumas mudanças nos tecidos, como epiderme e ou mesófilo, que fazem o inseto retirar o estilete da planta, mas essas mudanças não são de natureza mecânica, porque o estilete dos insetos atinge os vasos do floema em tempo similar ao das plantas sem aplicação de silício o que sugere que as mudanças químicas ocorrem após a absorção desse mineral.

Também foi verificado que o número de gotas excretadas pelos afídeos que se alimentam em plantas com silício diminui 
quando comparado com as plantas não tratadas com esse mineral, o que caracteriza uma diminuição da ingestão de seiva e possível mecanismo de antixenose bioquímica envolvido no processo de defesa das plantas.

A partir desses estudos, é possível definir e classificar os tipos de barreiras ou defesas que atuam em insetos sugadores e mastigadores, e qual seria a relação entre a sua alimentação e o efeito da aplicação do silício como micronutriente em plantas hospedeiras.

Assim, verifica-se que ocorrem dois tipos de barreiras ou defesas quando se utiliza o silício no controle de insetos-praga: para insetos mastigadores e para insetos sugadores.

\section{CONSIDERAÇÕES FINAIS}

Os insetos são os principais consumidores da produção primária terrestre, constituindo cerca de $80 \%$ da vida animal e, aproximadamente, um terço de todas as espécies conhecidas. Alguns apresentam hábito herbívoro, ao menos em uma fase do seu ciclo de vida desempenhando um importante papel ecológico. Por ser um grupo bastante numeroso, apresentam elevada densidade e diversidade em termos de ambientes e habilidades para a dispersão e muitos acabam por tornarem-se pragas de grande importância em diferentes culturas devido a diversos fatores.

As plantas podem apresentar mecanismos que as tornam resistentes a insetos-praga. A resistência pode ser caracterizada por mudanças na anatomia da planta ou por mudanças fisiológicas e bioquímicas, que podem induzir a formação de barreiras mecânicas ou químicas.

A utilização de silício apresenta grande importância econômica no controle de insetos-praga. Muitos estudos vêm sendo realizados com o intuito de esclarecer seu papel na nutrição e na proteção de plantas. As pesquisas demonstram o envolvimento do silício em vários aspectos estruturais, fisiológicos e bioquímicos das plantas com papéis bastante diversos.

O silício tem alto potencial de uso, pois além de promover melhoria no metabolismo da planta, ativa genes envolvidos na produção de enzimas relacionadas com os mecanismos de defesa contra insetos.

A principal vantagem da utilização, ou seja, do emprego do silício juntamente a adubação de diversas culturas é a sua especificidade, pois além de não causar efeito negativo aos inimigos naturais dos insetos-praga, quando utilizado nas doses recomendadas, não são considerados tóxicos ao homem e apresentam compatibilidade de uso com outras técnicas ou formas de controle.

A partir da revisão bibliográfica realizada foi possível verificar que há dois tipos de defesas ou barreiras envolvidas na resistência de plantas, a mecânica em relação a insetos mastigadores e a química em relação aos sugadores. Isto torna-se fundamental na tomada de medidas para controle efetivo de insetos em culturas, pois a partir do estudo da biologia e hábitos alimentares do inseto, seja ele mastigador ou sugador, adapta-se à forma mais eficaz de aplicação do silício (via solo ou foliar), dosagens adequadas, época ideal de aplicação que associadas a outras táticas de manejo podem ser efetivas no controle.

Ainda há necessidade de estudos para elucidar com precisão as causas de resistência envolvidas na utilização desse micronutriente, incluído recentemente na legislação como benéfico. Entretanto, a tecnologia para implantação da utilização de um produto natural como este se revela promissora e eficaz na redução da severidade de diversos insetos-praga. A inclusão da adubação silicatada no manejo nutricional da planta pode ainda significar 
culturas mais saudáveis, mais resistentes a estresses e mais produtivas.

\section{REFERÊNCIAS BIBLIOGRÁFICAS}

ADLAKA, P.A1964.. Studies of the various factors responsible for resistance to top borer on different varieties of sugarcane. Indian Journal Sugarcane Research Development, v. 83, p. 343344.

ALMEIDA CORTEZ, J. 2005Herbivoria e mecanismos de defesa vegetal. In: Nogueira, R.J.M.C. Araújo, E.L. Willadino L.G., Cavalcante, U.M.T. (Org.). Estresses ambientais: danos e benefícios em plantas, p.389-396..

BARBER, D.A.; SHONE M.G.T. 1966.The absorption of silica from aqueous solutions by plants. Journal of Experimental Botany, v. 17, p. 569578.

BARKER, G.M. 1989Grass host preferences of Listronotus banariensis (Coleoptera: Curculionidae). Journal Economic Entomology, v.82, p. 18071816.

BASAGLI, M. A. B.; MORAES, J. C.; CARVALHO, G. A.; ECOLE, C. C.; GONÇALVES-GERVÁSIO, R. C. R. 2003.Effect of sodium silicate application on the resistance of wheat plants to green-aphids Schizaphis graminum (Rond.) (Hemiptera: Aphididae). Neotropical Entomology, v.32, n.4, p.659-663.

BÉLANGER, R.R.; BOWEN, P.A.; EHRET, D.L.; MENZIES, J.G. 1995.Soluble silicon - its role in crop and disease management of greenhouse crops. Plant Disease, v. 79, n.4, p.329-336.

BLUM, A. 1968.Anatomical phenomena in seedlings of sorghum varieties resistant to the sorghum shoot fly Atherigona varia soccata. Crop Science, v. 8, p. 388-391.

BOIÇA JÚNIOR, A.L.; ALONSO, A.M. 2000.Efeito da adubação na manifestação da resistência de feijoeiro ao ataque de caruncho em testes com e sem chance de escolha. Bragantia, v. 59, n. 1, p. 35-43.

BORTOLI, S. A.. MAIA, I. G. 1994.Influência da aplicação de fertilizantes na ocorrência de pragas. In: Importância da adubação na qualidade dos produtos agrícolas. Icone, São Paulo, p. 53-63.

CAMARGO, J.M.M.; MORAES, J. C.; OLIVEIRA, E. B.; IEDE, E. T. 2008.Resistência induzida ao pulgãogigante-do-pinus (Hemiptera: Aphididae) em plantas de Pinus taeda adubadas com silício. Bragantia, v.67, n.4, p.927-932.

CARVALHO, S.K.; MORAES, J.C.; CARVALHO, J.G. 1999.Efeito do silício na resistência do sorgo (Sorghum bicolor) ao pulgão-verde Schizaphis graminum (Rondani) (Homoptera: Aphididae). Anais da Sociedade Entomológica do Brasil, v.28, p.505-510.

CHÉRIF, A.; ASSELIN, A.; BÉLANGER, R.R. 1994.Defense responses induced by soluble silicon in cucumber roots infected by Pythium spp. Phytopathology, v.84, p.236-242.

CHÉRIF, M.; BÉLANGER, R.R. 1992.Use of potassium silicate amendments in recirculating nutrient solutions to suppress Pythium ultimum on long English cucumber. Plant Disease, v.76, n.10, p.1008-11.

COLEY, P.D.; BARONE, J.A. 1996. Herbivory and plant defenses in tropical forests. Annual Review of Ecology and Systematics, v. 27, p. 305-335. 
COMHAIRE, M. 1965.El papel de la silica para los vegetales. Ann. Inst. Biol. Univ. Nac. México,v. 25, p. 35-38.

CORREA, R.S.B.; MORAES, J.C.; AUAD, A.M.; CARVALHO, G.A. 2005.Silicon and acibenzolar-s-methyl as resistance inducers in cucumber, against the whitefly Bemisia tabaci (Gennadius) (Hemiptera: Aleyrodidae) biotype B. Neotropical Entomology, v. 34, p. 429-433.

DAL POGETTO, M.H.F.A.; WILCKEN, C. F.; LIMA, A. C. V.; CHRISTOVAM, R. S. 2007.Efeito da aplicação de Agrosilício em mudas de Eucalyptus camaldulensis no desenvolvimento biológico de Glycaspis brimblecombei (Hemiptera: Psyllidae). Anais... IV Simpósio Brasileiro Sobre Silício na Agricultura, 2007, Botucatu. Resumos, 2007. p. 210-213.

DATNOFF, L.E.; SNYDER, G.H.; KORNDÖRFER, G.H. 2001. Silicon in Agriculture. Amsterdam: Elsevier, 403p.

DJAMIN, A.; PATHAK, M.D. 1967.Role of silica in resistance to Asiatic rice borer, Chilo supressalis (Walker), in rice varieties. Journal of Economic Entomology. v.60, n.2, p.347-351,

EDWARDS, P.J.; WRATTEN, S.D.1981. Ecologia das interações entre insetos e plantas. Fonseca VLI (Trad.) EPU, 71 pp. São Paulo.

ELAWAD, S.H.. GREEN JUNIOR, V.E. 1979.Silicon and the rice plant environment: a review of recent research. Il Riso. v.28, p.235-253.

EPSTEIN, E. 1999.Silicon. Annual Review of Plant Physiology and Plant Molecular Biology. v.50, p.641-664..

EPSTEIN, E. 1994.The anomaly of silicon in plant biology. Proceedings of National Academy of Sciences of the United States of America. v.91, p.1117.
EVANS, A.C. 1937.Physiological relationships between insects and their host plants. Rothamsted Experimental Station, Harpenden. p.558-572.

FADINI, M.A.M.. LEMOS, W.P.. PALLINI, A.. VENZON, M.. MOURÃO, S.A. 2004. Herbivoria de Tetranychus urticae Koch (Acari: Tetranychidae) induz defesa direta em morangueiro?

Neotropical

Entomology. v. 33, p. 293-297.

FERNANDES, G.W. 1994. "Plant mechanical defenses against insect herbivory". Revista Brasileira de Entomologia v.38, p. 421- 433.

GALLO, D.; NAKANO, O.; NETO, S.S.; CARVALHO, R.P.L.; BATISTA, G.C.; FILHO, E.B.; PARRA, J.R.P.; ZUCCHI, R.A.; ALVES, S. B., VENDRAMIM, J.D.; MARCHINI, L.C.; LOPES, J.R.S.; OMOTO, C. 2002.Entomologia agrícola. Piracicaba, FEALQ, 920p.

GOMES, F.B.; MORAES, J.C.; SANTOS, C.D.; GOUSSAIN, M.M. 2005.Resistance induction in wheat plants by silicon and aphids. Scientia Agricola (Piracicaba). v. 62, n.6, p.547-551.

GOUSSAIN, M.M.; MORAES, J.C.; CARVALHO, J.G.; NOGUEIRA, N.L.; ROSSI, M.L. 2002.Efeito do silício em plantas de milho no desenvolvimento biológico da lagartado-cartucho Spodoptera frugiperda (J.E. Smith) (Lepidoptera: Noctuidae). Neotropical Entomology. n.31, p. 305-310,.

GOUSSAIN, M.M.; PRADO, E.; MORAES, J. C. 2005.Effect of silicon applied to wheat plants on the biology and probing behaviour of the greenbug Schizaphis graminum (Rondani) (Hemiptera:Aphididae). Neotropical 
Entomology. v.34, n.5, p.807-813.

HANISCH, H.C. 1980.Zun einfluss der stickstoffdungung und vorbeugender spritzung von natronwasser glas zu weizenpflanzem auf deren widerstandsfahigkeit gegen getreideblattlause. Kali-Driefe, v.15, 287-296

HARBONE, J.B. 1988. Introduction to ecological biochemistry. $4 \mathrm{a}$ ed. Academic Press, London. 318 pp.

KARBAN, R.; MEYER, J. 1989.Induced plant responses to herbivory. Annual Review of Ecology and Systematics, v. 20, p. 341-348.

KERSTIENS, G. 1996.Signaling across the divide: a wider perspective of cuticular structure function relationships. Trends in Plant Science, v.1, p. 124128.

KIN, H.S.; HEINRICHS, E.A. 1982.Effects of silica level on whitebacked planthopper. International Rice Research Newsletter, v.7, p.17.

KORNDÖRFER, G.H.; LEPSCH, I.1999. Effect of silicon on plant growth and yield. Silicon in Agriculture. 26-30 Sept., Fort Lauderdale, Fl. 1999.

LABROUSSE, F. 1932. La fecondité du sol. Paris, Annales, Agronomiques, 311p..

LANNING, F. C.; LINKO, Y. 1961.Absorption and deposition of silica by four varieties of sorghum. Journal Agricultural Food Chemistry, v. 9, n. 6, p. 463-465.

LARA, F.M. 1991.Princípios de resistência de plantas à insetos. 2.ed. São Paulo, Ícone. $331 \mathrm{p}$.

LIMA FILHO, O.F. 2009. O silício e a resistência das plantas ao ataque de fungos patogênicos. http://www.embrapa.br/noticias/artigos folder.2005-artigo Review of recent research. Revista IL RISO 28:235-253. Acesso em: 14 mai.2009.

LIMA FILHO, O.F.; LIMA, M.T.G.; TSAI, S.M. 1999.O silício na agricultura. p.1-7. (Encarte Técnico - Informe Agronômico, 87).

LOWMAN, M.D. 1985.Temporal and spatial variability in insect grazing of the canopies of five Australian rainforest tree species. Australian Journal of Ecology, v. 10, p.724.

MARSCHNER, H. 1995. Mineral nutrition in higher plants. London: Academic Press. 889p.

MAXWELL, F.G. 1972.Host plant resistance to insects: nutritional and pest management relationships. In: Rodriguez, J.G. Insect and mite nutrition. Amsterdam: North-Holland, p.599-609.

Mc NAUGHTON, S.J.; TARRANTS, J.L. 1983.Grass leaf silification: natural selection selection for an inducible defense against herbivores. Proceedings of Natural Sciences, $n$. 80, p. 790-791.

MELO, M.O.; SILVA-FILHO, M.C. 2002.Plant-insect interaction: an evolutionary arms race between two distinct defense mechanisms. Brazilian Journal of Plant Physiology, v. 14, p. 7181.

MORAES, J.C.; GOUSSAIN, M.M.; BASAGLI, M.A.B. 2004.Silicon influence on the tritrophic interaction: wheat plants, the greenbug Schizaphis graminum (Rondani) (Hemiptera: Aphididae), and its natural enemies, Chrysoperla externa (Hagen) (Neuroptera: Chrysopidae) and Aphidius colemani viereck (Hymenoptera: Aphidiidae). Neotropical Entomology, v. 33, n. 5, p. 619-624.

MORAES, J.C.; GOUSSAIN, M.M.; CARVALHO, G.A.; COSTA, R.R. 2005.Feeding non-preference of the corn leaf aphid Rhopalosiphum maidis (Fitch, 1956) (Hemiptera: Aphididae) to corn plants (Zea mays L.) treated 
with silicon. Ciência e Agrotecnologia, n. 29, p.761-766.

PAIS, M.P. 2003. Artrópodos e suas relações de herbivoria como bioindicadores nos primeiros estágios de uma recomposição florestal estacional semidecidual em Ribeirão Preto, SP. 115 f. Tese (Doutorado) - Faculdade de Filosofia, Ciências e Letras de Ribeirão Preto da USP, São Paulo.

PATRIQUIN, D.G.; BAINES, D.; ABBOUD, A. 1993.Soil fertility effects on pests and diseases. In: COOK, H.F.; LEE, H.C. (Eds.). Proceedings of the Third International Conference on Sustainable Agriculture. Londres: Wye College Press, p. 161-174. 1993.

PRIMAVESI, A.M. 1988.Manejo ecológico de pragas e doenças. São Paulo: Nobel, $137 \mathrm{p}$.

RAVEN, H. P.; EVERT, F.R.; EICHHORN, S.E1996.. Biologia Vegetal. Editora Guanabara Koogan S.A. Rio de Janeiro, 587p.

RAVEN, J.A. The transport and function of silicon in plants. 1983.Biological Reviews of the Cambridge Philosophical Society, v.58, p.179207.

RHOADES, D. F. 1979.Evolution of plant chemical defense against herbivores. In: Rosenthal, G. A. and Janzen, D. H. (eds), Herbivores: their interaction with secondary plant metabolites. Academic Press, London, pp. 3-54.

RHODES, M. J. C. 1994.Physiological roles for secondary metabolites in plants: some process, many outstanding problems. Plant Molecular Biology, v. 24, p. 1-20.

RODRIGUES, F.; DATNOFF, L.E.; KORNDÖRFER, G.H.; SEEBOLD, K.W.; RUSH, M.C. 2001.Effect of silicon and host resistance on sheath blight development in rice. Plant Disease, v. 85, p.827-832.

SALIM, M.; SAXENA, R.C. 1992Iron, silica and aluminum stresses and varietal resistance in rice: effects on whitebacked planthopper. Crop Science, v.32, p.212-219..

SAMUELS, A.L. 1993.The effects of silicon supplementation on cucumber fruit: changes in surface characteristics. Annals of Botany, v.72, p.433-440.

SANTOS, R.I. 2004.Metabolismo básico e origem dos metabólitos secundários. In: Simões, C.M.O.. Schenkel, E.P. Gosmann, G.. Mello, J.C.P. de. Mentz, L.A.. Petrovick, P.R. Farmacognosia: da planta ao medicamento. $5^{\text {a }}$ ed. Editora da UFSC/UFSC. p. 403- 434.

SARGERS, C.L.; COLEY, P.D. 1995.Benefits and costs of plant defense in a neotropical shrub. Ecology, v.76, p.1835-1843.

SAVANT, N.K.; SNYDER, G.D.; DATNOFF, L.E.1997.. Silicon in management and sustainable rice production. Advances in Agronomy, v. 58, p. 151-199.

SAWANT, A.S.; PATIL, V.H.; SAVANT, N.K. 1994.Rice hull ash applied to seedbed reduces deadhearts in transplanted rice. International Rice Research Notes, v.19, p. 20-21.

SILVEIRA, R.L.V.A.; HIGASHI, E.N. 2003.Aspectos nutricionais envolvidos na ocorrência de doenças com ênfase para o eucalipto. Circular Técnica IPEF. n.200, p.1-13.

SUBRAMANIAN, S.; GOPALASWAMY, A. 1988.Effect of silicate materials on rice crop pests. International Rice Research Newsletter, v.13, p. 32.

TAKAHASHI, E. T.; KUMAZAWA, K.; ISHII, R.; ISHIHARA, K.; HIRATA, $\mathrm{H}$ (Ed.). 1984.Science of the rice uptake mode and physiological functions of silica. In: MATSUO, 
TAYABI, K. \& AZIZI, P. Influence of silica on rice yield and stem-borer (Chilo supremain) in Rasht/Iran 1979-1980. Pesticides, v. 18, p.20-22.

TAYABI, K.; AZIZI, P. 1984.Influence of silica on rice yield and stem-borer (Chilo supremain) in Rasht/Iran 19791980. Pesticides, v. 18, p. 20-22.

THOMAZINI, M. J.; THOMAZINI, A.P.B.W. 2000. A fragmentação florestal e a diversidade de insetos nas florestas tropicais úmidas. Embrapa Acre, (Embrapa Acre. Documentos, 57), Rio Branco, 21pp.

VAN EMDEN , H.F. 1966.Studies on the relations of insect and host plant. III. a comparison of the reproduction of Brevicoryne brassicae and Myzus persicae. (Hemiptera:Aphididae) on Brussels sprout plant supplied with different rates of nitrogen and potassium.
Experimentalis et Applicata, v.9, p.444-460.

WERNER, D.; ROTH, R. Silica metabolism. In: LÄUCHLI, A. BIELESKI, R.L (Ed.). 1983.Encyclopedia of plant physiology, New Series, Berlin: Springer-Verlag, v. 15b,p. 682-694.

WHITE, T. C. R. 1969.An index to measure weather-induced stress of trees associated with outbreaks of psyllids in Australia. Ecology, v.50, p.905-909.

WILD, A. 1988. Russel's soil conditions and plant growth. 11 ed. London: Longman, 991p.

YOSHIDA, S. 1975.The physiology of silicon in rice. Food and Fertilizer Technology Center Taipei. Taiwan. (Technical bulletin, 25).

YOSHIDA, S.; OHNISHI, Y.; KITAGISHI, K. 1962.Histochemistry of silicon in rice plant. Soil Science and Plant Nutition, v. 8, p. 107-111. 